\title{
Low Temperature Calorimetry of 3-Fluoro-5-(3-pyridinyloxy) Benzenamine and N-[3-Fluoro-5-(3-Pyridinyloxy)Phenyl]-N'-3-Pyridinyl Urea
}

\author{
Rongchun Li, ${ }^{\text {a }}$ Keyan Sun, ${ }^{\mathrm{b}}$ Yushan Hua, ${ }^{\mathrm{a}}$ Zhicheng Tan, ${ }^{\mathrm{b}}$ Quan Shi ${ }^{\mathrm{b}, *}$ \\ ${ }^{a}$ Key Laboratory of Coordination Chemistry and Functional Materials, College of Chemistry and Chemical \\ Engineering, Dezhou University, Dezhou, Shandong 253023, China \\ ${ }^{\mathrm{b}}$ Thermochemistry Laboratory, Liaoning Province Key Laboratory of Thermochemistry for Energy and Materials, \\ Dalian National Laboratory for Clean Energy, Dalian Institute of Chemical Physics, \\ Chinese Academy of Sciences, Dalian 116023, China \\ *E-mail: shiquan@dicp.ac.cn
}

Received 13 February 2017, Revised 01 August 2017, Accepted 01 August 2017

\begin{abstract}
The investigation on thermodynamic properties of drug intermediates plays a crucial role in the design and synthesis of new drugs as well as understanding their biological activities in vivo. In this work, the thermodynamic properties of two drug intermediates of 3-fluoro-5-(3-pyridinyloxy) benzenamine and N-[3-fluoro-5-(3pyridinyloxy)phenyl]-N'-3-pyridinyl urea were studied by means of low temperature calorimety performed in a Physical Property Measurement System calorimeter. The heat capacities of these two compounds were measured over the temperature region from (1.9 to 300) $\mathrm{K}$, and the corresponding thermodynamic functions were consequently calculated on the basis of the heat capacity curve fitting. Additionally, a group additivity method were employed for estimating the heat capacity values of these two compounds at $298.15 \mathrm{~K}$, which are in good agreement with the values measured in this work.
\end{abstract}

Keywords: 3-fluoro-5-(3-pyridinyloxy) benzenamine; N-[3-fluoro-5-(3-pyridinyloxy)phenyl]-N'-3-pyridinyl urea; low temperature calorimetry; heat capacity; thermodynamic properties.

\section{Introduction}

3-fluoro-5-(3-pyridinyloxy) benzenamine (FPB) and N[3-fluoro-5-(3-pyridinyloxy)phenyl]-N'-3-pyridinyl urea (FPU) are two important drug intermediates which are generally used in the field of health professionals and pharmaceutical industry [1-5]. The molecular structures of these two compounds are shown in Scheme 1. Most importantly, FPB and FPU are generally employed as structural scaffolds for design and synthesis of anticancer drugs, antibacterial agents and other new medicines for diabetes and heart disease [6-7]. For example, the first, selective, small molecule activator of cardiac myosin has been successfully synthesized based on FPB and FPU for the treatment of systolic heart failure [7]. On the other hand, the design and synthesis of new drugs as well as study and understanding their biological activities behaving in vivo are in urgent need of their thermodynamic properties [8-9], and therefore the thermodynamic investigation on these two compounds are necessary in the related research field.

Low temperature calorimetry has been usually used to obtain the heat capacity of condensed matters, with which the corresponding entropy, enthalpy and Gibbs energy can be consequently calculated [10-13]. However, as far as we known, the low temperature calorimetric study on FPB and FPU has never been reported in literature. In the present work, we have measured the heat capacities of FPB and FPU using a Physical Property Measurement System
(PPMS) calorimeter in the temperature range from (1.9 to $300) \mathrm{K}$, and the heat capacity data has been fitted to a series of theoretical models and polynomial functions. The thermodynamic functions over the temperature region from ( 0 to 300$) \mathrm{K}$ have been calculated using the heat capacity fitting parameters. Additionally, the experimental heat capacity data of FPB and FPU at 298.15 K have also been compared with those estimated using the Chickos' group additivity model.

\section{Experimental}

The FPB and FPU samples used in this study were synthesized according to the route reported previously in literature [7]. The detailed synthesis procedure has been presented in the supplementary information (SI). Consequently, the as-prepared samples were further characterized using the HPLC/MS and ${ }^{1} \mathrm{NMR}$ techniques; FPB: ${ }^{1} \mathrm{H}$ NMR (300 MHz, DMSO- $d_{6}$ ) ppm 8.38-8.50 (m, $2 \mathrm{H}), 7.42-7.51(\mathrm{~m}, 2 \mathrm{H}), 6.10-6.14(\mathrm{~d}, J=12 \mathrm{~Hz}, 1 \mathrm{H}), 6.00$ (s, 2H), 5.63 (s, 2H); FPB: LCMS (ES, $m / z) 205.0[\mathrm{M}+$ $\mathrm{H}]^{+}$; FPU: ${ }^{1} \mathrm{H}$ NMR (400 MHz, DMSO-d $d_{6}$ ppm 9.17 $(\mathrm{s}, 1 \mathrm{H}), 8.91(\mathrm{~s}, 1 \mathrm{H}), 8.57(\mathrm{~d}, J=2.5 \mathrm{~Hz}, 1 \mathrm{H}), 8.43-8.49(\mathrm{~m}$, $2 \mathrm{H}), 8.21(\mathrm{dd}, J=4.7,1.4 \mathrm{~Hz}, 1 \mathrm{H}), 7.91$ (ddd, $J=8.3,2.6$, $1.5 \mathrm{~Hz}, 1 \mathrm{H}), 7.58$ (ddd, $J=8.4,2.81 .4 \mathrm{~Hz}, 1 \mathrm{H}), 7.49$ (dd, $J$ $=8.4,4.6 \mathrm{~Hz}, 1 \mathrm{H}), 7.32(\mathrm{dd}, J=8.3,4.7 \mathrm{~Hz}, 1 \mathrm{H}), 7.20(\mathrm{dt}$, $J=11.3,2.1 \mathrm{~Hz}, 1 \mathrm{H}), 6.93(\mathrm{~s}, 1 \mathrm{H}), 6.59(\mathrm{dt}, J=9.9,2.3 \mathrm{~Hz}$, 1H); FPU: LCMS (ES, $m / z) 325.1\left[\mathrm{M}+\mathrm{H}^{+}\right]$. These results indicate that the molecular structures of as-prepared samples 
Table 1. Description of FPB and FPU samples

\begin{tabular}{|c|c|c|c|c|}
\hline Sample & Molecular formula & CAS No. & Source & ${ }^{\mathrm{a}}$ Mass fraction purity \\
\hline FPB & $\mathrm{C}_{11} \mathrm{H}_{9} \mathrm{FN}_{2} \mathrm{O}$ & 791644-59-2 & Synthesized in-house & 0.986 \\
\hline FPU & $\mathrm{C}_{17} \mathrm{H}_{13} \mathrm{FN}_{4} \mathrm{O}_{2}$ & $1241384-88-2$ & Synthesized in-house & 0.996 \\
\hline
\end{tabular}

${ }^{\mathrm{a}}$ The mass fraction purity was measured using a HPLC/MS.<smiles>Nc1cc(F)cc(Oc2cccnc2)c1</smiles>

(A) 3-fluoro-5-(3-pyridinyloxy) benzenamine<smiles>O=C(Nc1cccnc1)Nc1cc(F)cc(Oc2cccnc2)c1</smiles>

(B) N-[3-fluo 10-5-(3-pyridinyloxy)phenyl]-N-3-pyridinyl urea

Figure 1. Molecular structures of FPB (A) and FPU studied in this work.

are those shown in Figure 1. The more descriptions including the purity of the two samples determined by LCMS are listed in Table 1.

The low temperature calorimetric measurement was performed using a Quantum Design PPMS equipped with a thermal relaxation heat capacity option. The heat capacity measurement accuracy was determined to be $\pm 3 \%$ in the temperature region from 1.9 to $20 \mathrm{~K}$ and $\pm 3 \%$ from 20 to $400 \mathrm{~K}$ by measuring the heat capacities of standard materials of copper pellet, $\alpha-\mathrm{Al}_{2} \mathrm{O}_{3}$ (SRM720) and benzoic acid (SRM39j) [14]. The heat capacities of FPB and FPU were measured using a logarithmic temperature interval in the region from 1.9 to $100 \mathrm{~K}$ and $10 \mathrm{~K}$ interval from 100 to $300 \mathrm{~K}$. The detailed sample preparation and measurement procedure can be found in the previous publications [1516]. The sample masses used in the heat capacity measurement are $13.32 \mathrm{mg}$ and $7.88 \mathrm{mg}$ for FPB and FPU, respectively.

\section{Results and Discussion}

The collected heat capacity data of FPB and FPU from the PPMS calorimeter are listed in Table 2 and plotted in Figure 2. It can be seen from the figure that the heat capacity of these two compounds gradually increase with the temperature increasing, and on any thermal anomalies could be detected in the entire temperature region. Also, the FPB sample behaves a smaller heat capacity tendency due to its smaller molecular weight than that of FPU.

To calculate the thermodynamic functions of FPB and FPU, we have fitted the heat capacity data to different models in the following three temperature region. In the temperature region below $10 \mathrm{~K}$, the heat capacity was fitted using a theoretical model [17-18]:

$C_{p, m}^{o}=B_{3} T^{3}+B_{5} T^{5}+B_{7} T^{7}+B_{9} T^{9}$

where these odd-power terms in temperature represent the lattice vibration heat capacity contribution at low temperatures. In the middle temperature region from (10 to
60) $\mathrm{K}$, the heat capacity was fitted to the following orthogonal polynomial function [19]:

$C_{p, m}^{o}=A_{0}+A_{1} T+A_{2} T^{2}+A_{3} T^{\underline{3}}+A_{4} T^{4}+A_{5} T^{5}+A_{6} T^{6}$

In the high temperature region above $60 \mathrm{~K}$, the heat capacity was fitted to a combination of Debye and Einstein function [20]:

$C_{p, m}^{o}=n_{D} D\left(\theta_{D}\right)+m_{E}\left(\theta_{E}\right)+a T+b T^{2}$

where $n_{D}$ and $n_{E}$ are Debye and Einstein parameters, $D\left(\theta_{D}\right)$ and $E\left(\theta_{E}\right)$ are Debye and Einstein functions, $\theta_{D}$ and $\theta_{E}$ are Debye and Einstein temperatures, and the term of $(a T+$ $\left.b T^{2}\right)$ represents a correction for the difference of $\left(C_{p}-C_{v}\right)$.

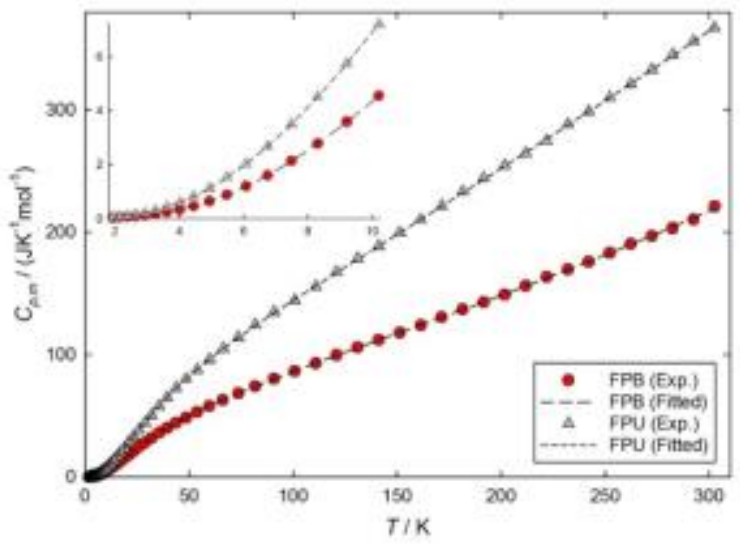

Figure 2. The collected heat capacity data of FPB and FPU from the PPMS calorimeter.

Table 2. Experimental molar heat capacities at constant pressure for FPB and FPU from 1.9 to $300 \mathrm{~K}^{a}$

\begin{tabular}{cccc}
\hline \multicolumn{3}{c}{$\mathrm{FPB}$} & \multicolumn{2}{c}{$\mathrm{FPU}$} \\
\hline$T / \mathrm{K}$ & $\begin{array}{c}C^{\mathrm{o}}{ }_{p, m} / \\
\left(\mathrm{J} \cdot \mathrm{K}^{-1} \cdot \mathrm{mol}^{-1}\right)\end{array}$ & $T / \mathrm{K}$ & $\begin{array}{c}C^{\mathrm{o}}{ }_{p, m} / \\
\left(\mathrm{J} \cdot \mathrm{K}^{-1} \cdot \mathrm{mol}^{-1}\right)\end{array}$ \\
\hline 1.93 & 0.034239 & 1.93 & 0.062297 \\
2.14 & 0.047027 & 2.14 & 0.084902 \\
2.38 & 0.065455 & 2.38 & 0.11905 \\
2.64 & 0.090328 & 2.64 & 0.16547 \\
2.93 & 0.12556 & 2.93 & 0.23159 \\
3.25 & 0.17557 & 3.25 & 0.32207 \\
3.61 & 0.24496 & 3.61 & 0.44644 \\
4.01 & 0.34029 & 4.01 & 0.61414 \\
4.45 & 0.47207 & 4.45 & 0.84110 \\
4.93 & 0.65213 & 4.93 & 1.1422 \\
5.48 & 0.89095 & 5.47 & 1.5390 \\
6.07 & 1.2062 & 6.07 & 2.0495 \\
6.74 & 1.6110 & 6.74 & 2.6867 \\
7.48 & 2.1346 & 7.48 & 3.5088 \\
8.30 & 2.7875 & 8.30 & 4.5281 \\
9.21 & 3.5903 & 9.20 & 5.7549 \\
10.21 & 4.5531 & 10.21 & 7.2157 \\
\hline & & &
\end{tabular}




\begin{tabular}{|c|c|c|c|}
\hline 11.30 & 5.7284 & 11.30 & 8.9930 \\
\hline 12.55 & 7.1280 & 12.54 & 11.127 \\
\hline 13.92 & 8.7810 & 13.92 & 13.637 \\
\hline 15.44 & 10.707 & 15.44 & 16.522 \\
\hline 17.15 & 12.905 & 17.15 & 19.942 \\
\hline 19.03 & 15.401 & 19.02 & 23.825 \\
\hline 21.12 & 18.194 & 21.11 & 28.250 \\
\hline 23.44 & 21.223 & 23.45 & 32.988 \\
\hline 26.01 & 24.562 & 26.01 & 38.356 \\
\hline 28.88 & 28.127 & 28.89 & 44.242 \\
\hline 32.06 & 31.802 & 32.06 & 50.516 \\
\hline 35.55 & 35.922 & 35.55 & 57.664 \\
\hline 39.46 & 40.051 & 39.46 & 64.913 \\
\hline 43.80 & 44.263 & 43.79 & 72.439 \\
\hline 48.61 & 48.443 & 48.60 & 80.017 \\
\hline 53.94 & 53.009 & 53.97 & 87.547 \\
\hline 59.86 & 57.774 & 59.88 & 95.782 \\
\hline 66.43 & 62.892 & 66.45 & 104.70 \\
\hline 73.75 & 68.228 & 73.75 & 113.95 \\
\hline 81.85 & 74.217 & 81.86 & 124.44 \\
\hline 90.84 & 80.210 & 90.85 & 134.59 \\
\hline 100.78 & 86.337 & 100.81 & 144.26 \\
\hline 110.94 & 92.870 & 110.96 & 155.47 \\
\hline 120.99 & 99.588 & 120.99 & 167.44 \\
\hline 131.09 & 105.90 & 131.05 & 178.34 \\
\hline 141.17 & 111.92 & 141.20 & 188.34 \\
\hline 151.31 & 117.95 & 151.28 & 199.31 \\
\hline 161.41 & 124.14 & 161.41 & 210.08 \\
\hline 171.49 & 130.40 & 171.48 & 221.46 \\
\hline 181.60 & 136.82 & 181.54 & 233.14 \\
\hline 191.69 & 142.90 & 191.61 & 244.16 \\
\hline 201.78 & 148.94 & 201.75 & 254.42 \\
\hline 211.90 & 156.23 & 211.85 & 264.37 \\
\hline 221.99 & 163.32 & 221.99 & 274.61 \\
\hline 232.12 & 169.80 & 232.06 & 288.30 \\
\hline 242.15 & 175.83 & 242.11 & 298.58 \\
\hline 252.30 & 183.23 & 252.21 & 309.78 \\
\hline 262.37 & 190.49 & 262.34 & 320.95 \\
\hline 272.43 & 197.08 & 272.43 & 332.74 \\
\hline 282.52 & 203.27 & 282.43 & 345.20 \\
\hline 292.65 & 210.44 & 292.56 & 355.95 \\
\hline 302.66 & 221.14 & 302.61 & 367.07 \\
\hline
\end{tabular}

${ }^{a}$ The expanded uncertainties in the value of the heat capacities are $\pm 0.03 C_{p, m}^{o}$ from $T=1.9$ to $20 \mathrm{~K}$ and \pm 0.01 $C_{p, m}^{o}$ from $T=20$ to $400 \mathrm{~K}$.

All the fitting parameters as well as \%RMS (percent root mean square) deviations from the fitting models are listed in Table 3. The fitted heat capacity data are also plotted as a form of dashed line in Figure 2. The thermodynamic functions of FPB and FPU have been calculated using these fitting parameters and the corresponding thermodynamic relationship in the temperature region from (0 to 300$) \mathrm{K}$. The calculated results are listed in Table 4 with $1 \mathrm{~K}$ interval below $10 \mathrm{~K}, 5$ $\mathrm{K}$ interval from (10 to 50$) \mathrm{K}$, and $10 \mathrm{~K}$ interval from (50 to $300) \mathrm{K}$, including the values at $273.15 \mathrm{~K}$ and $298.15 \mathrm{~K}$. The standard molar heat capacities, entropies and enthalpies at

298.15 $\mathrm{K}$ and $0.1 \mathrm{M} \mathrm{Pa}$ are consequently obtained to be $(216.03 \pm 2.16) \mathrm{J} \cdot \mathrm{K}^{-1} \cdot \mathrm{mol}^{-1},(234.13 \pm 2.34) \mathrm{J} \cdot \mathrm{K}^{-1} \cdot \mathrm{mol}^{-1}$ and $(34.107 \pm 0.341) \mathrm{kJ} \cdot \mathrm{mol}^{-1}$, respectively for $\mathrm{FPB}$, and $(362.32 \pm 3.62) \mathrm{J} \cdot \mathrm{K}^{-1} \cdot \mathrm{mol}^{-1},(391.15 \pm 3.91) \mathrm{J} \cdot \mathrm{K}^{-1} \cdot \mathrm{mol}^{-1}$ and $(57.508 \pm 0.575) \mathrm{kJ} \cdot \mathrm{mol}^{-1}$, respectively for FPU.

Table 3. Summary of the fitting parameters of heat capacities of FPB and FPU covering the entire temperature range from 1.9 to $300 \mathrm{~K}$.

\begin{tabular}{|c|c|c|}
\hline \multirow{2}{*}{$\begin{array}{c}\text { Fitting } \\
\text { Parameter }\end{array}$} & \multicolumn{2}{|c|}{ Coefficients } \\
\hline & FPB & FPU \\
\hline & below $5.40 \mathrm{~K}$ & below $5.22 \mathrm{~K}$ \\
\hline$B_{3}$ & $4.58523 \mathrm{E}-03$ & $8.51145 \mathrm{E}-03$ \\
\hline$B_{5}$ & $5.85969 \mathrm{E}-05$ & 8.38175E-05 \\
\hline$B_{7}$ & $-1.18862 \mathrm{E}-06$ & $-2.11694 \mathrm{E}-06$ \\
\hline \multirow{3}{*}{$B_{9}$} & $5.76668 \mathrm{E}-09$ & $1.11295 \mathrm{E}-08$ \\
\hline & $\% \mathrm{RMS}=0.82$ & $\%$ RMS $=1.66$ \\
\hline & from 5.40 to $55.50 \mathrm{~K}$ & from 5.22 to $60.9 \mathrm{~K}$ \\
\hline$A_{0}$ & $1.09647 \mathrm{E}+00$ & $1.07480 \mathrm{E}+00$ \\
\hline$A_{l}$ & $-6.69193 \mathrm{E}-01$ & $-7.66995 \mathrm{E}-01$ \\
\hline$A_{2}$ & $1.38109 \mathrm{E}-01$ & $1.85073 \mathrm{E}-01$ \\
\hline$A_{3}$ & $-4.55090 \mathrm{E}-03$ & $-5.91500 \mathrm{E}-03$ \\
\hline$A_{4}$ & 7.51603E-05 & $1.00649 \mathrm{E}-04$ \\
\hline$A_{5}$ & $-6.33689 \mathrm{E}-07$ & $-9.23387 \mathrm{E}-07$ \\
\hline \multirow[t]{3}{*}{$A_{6}$} & 2.17461E-09 & $3.55922 \mathrm{E}-09$ \\
\hline & $\%$ RMS $=0.15$ & $\% \mathrm{RMS}=0.25$ \\
\hline & above $55.50 \mathrm{~K}$ & above $60.90 \mathrm{~K}$ \\
\hline$n$ & 2.04 & 2.54 \\
\hline$\theta_{D}$ & 148.38 & 162.34 \\
\hline$m$ & 0.81 & 0.44 \\
\hline$\theta_{E}$ & 403.93 & 605.58 \\
\hline$a$ & 2.66533E-01 & $8.22201 \mathrm{E}-01$ \\
\hline \multirow[t]{2}{*}{$b$} & 7.75224E-04 & $5.27555 \mathrm{E}-04$ \\
\hline & $\%$ RMS $=0.30$ & $\%$ RMS $=0.33$ \\
\hline
\end{tabular}

Moreover, it should be pointed out that Chiockos et al. reported a group additivity method for the estimation of heat capacities of organic liquids and solids at $298.15 \mathrm{~K}$ [21-22], which could be used to estimate the heat capacity of FPB and FPU for the comparison with our values measured using the PPMS. The group values used for estimating the heat capacities of these two compounds are listed in Table 5, and then the heat capacity can be calculated by a sum of the values of all the corresponding groups included in the formula of FPB and FPU. As a result, the heat capacity of FPB at $298.15 \mathrm{~K}$ can be estimated to be $226.51 \mathrm{~J} \cdot \mathrm{K}^{-1} \cdot \mathrm{mol}^{-1}$ by assuming that it corresponds to the sum of the group values of $\left(7 *\left(=\mathrm{C}_{\mathrm{a}} \mathrm{H}-\right)+\right.$ $\left.4 *\left(=\mathrm{C}_{\mathrm{a}} \mathrm{R}-\right)+\left(-\mathrm{O}_{\mathrm{c}^{-}}\right)+\left(=\mathrm{N}_{\mathrm{c}^{-}}\right)+(-\mathrm{F})+\left(-\mathrm{NH}_{2}\right)\right)$, and the heat capacity of FPU to be $360.91 \mathrm{~J} \cdot \mathrm{K}^{-1} \cdot \mathrm{mol}^{-1}$ assuming the sum of values of $\left(11^{*}\left(=\mathrm{C}_{\mathrm{a}} \mathrm{H}-\right)+5^{*}\left(=\mathrm{C}_{\mathrm{a}} \mathrm{R}-\right)+\left(-\mathrm{O}^{-}\right)+\right.$ $\left.2 *\left(=\mathrm{N}_{\mathrm{c}^{-}}\right)+(-\mathrm{F})+(-\mathrm{NHCONH}-)\right)$. These estimated heat capacities are comparable with our measured values of $(216.03 \pm 2.16) \mathrm{J} \cdot \mathrm{K}^{-1} \cdot \mathrm{mol}^{-1}$ for FPB and $(362.32 \pm 3.62)$ $\mathrm{J} \cdot \mathrm{K}^{-1} \cdot \mathrm{mol}^{-1}$ for FPU. The deviations of the above estimated value from the measured are within $\pm 4.5 \%$ for FPB and $\pm 0.4 \%$ for FPU, suggesting that Chiockos' method could provide an estimation of heat capacities at $298.15 \mathrm{~K}$ with a high accuracy for condensed organic compounds [21]. 
Table 4. Standard thermodynamic functions of FPB and FPU from (0 to 300) $\mathrm{K}$. M= $204.20 \mathrm{~g} \cdot \mathrm{mol}^{-1}$ for FPB and 324.31 $g \cdot \mathrm{mol}^{-1}$ for $\mathrm{FPU}$

\begin{tabular}{|c|c|c|c|c|c|c|}
\hline \multirow[b]{2}{*}{$T / \mathrm{K}$} & \multicolumn{3}{|c|}{ FPB } & \multicolumn{3}{|c|}{ FPU } \\
\hline & $\begin{array}{c}C_{p, m}^{0} / \\
\left(\mathrm{J} \cdot \mathrm{K}^{-1} \cdot \mathrm{mol}^{-1}\right)\end{array}$ & $\begin{array}{c}\Delta_{0}^{T} S_{\mathrm{m}}^{0} / \\
\left(\mathrm{J} \cdot \mathrm{K}^{-1} \cdot \mathrm{mol}^{-1}\right)\end{array}$ & $\begin{array}{c}\Delta^{T}{ }_{0} H^{0}{ }_{\mathrm{m}} / \\
\left(\mathrm{kJ} \cdot \mathrm{mol}^{-1}\right)\end{array}$ & $\begin{array}{c}C_{p, m}^{0} / \\
\left(\mathrm{J} \cdot \mathrm{K}^{-1} \cdot \mathrm{mol}^{-1}\right)\end{array}$ & $\begin{array}{c}\Delta^{T}{ }_{0} S_{\mathrm{m}}^{0} / \\
\left(\mathrm{J} \cdot \mathrm{K}^{-1} \cdot \mathrm{mol}^{-1}\right)\end{array}$ & $\begin{array}{c}\Delta^{T}{ }_{0} H^{0}{ }_{\mathrm{m}} / \\
\left(\mathrm{kJ} \cdot \mathrm{mol}^{-1}\right)\end{array}$ \\
\hline 1 & $4.6426 \mathrm{E}-03$ & $1.5400 \mathrm{E}-03$ & $1.1559 \mathrm{E}-06$ & $8.5932 \mathrm{E}-03$ & $2.8536 \mathrm{E}-03$ & $2.1416 \mathrm{E}-06$ \\
\hline 2 & 0.038408 & 0.012581 & $1.8929 \mathrm{E}-05$ & 0.070509 & 0.023196 & $3.4873 \mathrm{E}-05$ \\
\hline 3 & 0.13555 & 0.043756 & $9.9030 \mathrm{E}-05$ & 0.24577 & 0.080040 & $1.8087 \mathrm{E}-04$ \\
\hline 4 & 0.33550 & 0.10720 & 3.2432E-04 & 0.59880 & 0.19411 & $5.8578 \mathrm{E}-04$ \\
\hline 5 & 0.67467 & 0.21566 & 8.1663E-04 & 1.1822 & 0.38582 & $1.4557 \mathrm{E}-03$ \\
\hline 6 & 1.1628 & 0.37977 & $1.7241 \mathrm{E}-03$ & 1.9813 & 0.66919 & $3.0220 \mathrm{E}-03$ \\
\hline 7 & 1.7886 & 0.60430 & 3.1887E-03 & 2.9721 & 1.0466 & $5.4833 \mathrm{E}-03$ \\
\hline 8 & 2.5395 & 0.89085 & $5.3430 \mathrm{E}-03$ & 4.1380 & 1.5178 & $9.0246 \mathrm{E}-03$ \\
\hline 9 & 3.3998 & 1.2386 & 8.3042E-03 & 5.4585 & 2.0800 & 0.013811 \\
\hline 10 & 4.3550 & 1.6455 & 0.012174 & 6.9149 & 2.7294 & 0.019987 \\
\hline 15 & 10.122 & 4.4567 & 0.047813 & 15.683 & 7.1212 & 0.075622 \\
\hline 20 & 16.686 & 8.2597 & 0.11470 & 25.821 & 13.003 & 0.17906 \\
\hline 25 & 23.279 & 12.695 & 0.21470 & 36.317 & 19.892 & 0.33440 \\
\hline 30 & 29.511 & 17.498 & 0.34687 & 46.609 & 27.429 & 0.54188 \\
\hline 35 & 35.241 & 22.484 & 0.50897 & 56.421 & 35.358 & 0.79968 \\
\hline 40 & 40.474 & 27.536 & 0.69845 & 65.639 & 43.500 & 1.1051 \\
\hline 45 & 45.282 & 32.585 & 0.91300 & 74.219 & 51.733 & 1.4550 \\
\hline 50 & 49.750 & 37.590 & 1.1507 & 82.147 & 59.969 & 1.8462 \\
\hline 60 & 57.996 & 47.399 & 1.6900 & 96.130 & 76.218 & 2.7395 \\
\hline 70 & 65.571 & 56.916 & 2.3083 & 109.38 & 92.060 & 3.7689 \\
\hline 80 & 72.681 & 66.140 & 2.9999 & 121.46 & 107.46 & 4.9237 \\
\hline 90 & 79.486 & 75.096 & 3.7609 & 132.97 & 122.44 & 6.1962 \\
\hline 100 & 86.072 & 83.813 & 4.5889 & 144.15 & 137.03 & 7.5820 \\
\hline 110 & 92.494 & 92.319 & 5.4818 & 155.12 & 151.28 & 9.0785 \\
\hline 120 & 98.791 & 100.64 & 6.4383 & 165.97 & 165.24 & 10.684 \\
\hline 130 & 105.00 & 108.79 & 7.4574 & 176.76 & 178.96 & 12.398 \\
\hline 140 & 111.16 & 116.80 & 8.5382 & 187.51 & 192.45 & 14.219 \\
\hline 150 & 117.29 & 124.68 & 9.6805 & 198.24 & 205.75 & 16.148 \\
\hline 160 & 123.43 & 132.44 & 10.884 & 208.99 & 218.89 & 18.184 \\
\hline 170 & 129.58 & 140.11 & 12.149 & 219.75 & 231.88 & 20.328 \\
\hline 180 & 135.78 & 147.69 & 13.476 & 230.53 & 244.75 & 22.579 \\
\hline 190 & 142.04 & 155.20 & 14.865 & 241.36 & 257.50 & 24.938 \\
\hline 200 & 148.36 & 162.65 & 16.317 & 252.22 & 270.16 & 27.406 \\
\hline 210 & 154.77 & 170.04 & 17.833 & 263.14 & 282.73 & 29.983 \\
\hline 220 & 161.28 & 177.39 & 19.413 & 274.12 & 295.22 & 32.669 \\
\hline 230 & 167.88 & 184.70 & 21.058 & 285.15 & 307.65 & 35.466 \\
\hline 240 & 174.59 & 191.99 & 22.771 & 296.26 & 320.02 & 38.373 \\
\hline 250 & 181.42 & 199.26 & 24.551 & 307.43 & 332.34 & 41.391 \\
\hline 260 & 188.37 & 206.51 & 26.399 & 318.68 & 344.62 & 44.521 \\
\hline 270 & 195.44 & 213.75 & 28.318 & 330.00 & 356.86 & 47.765 \\
\hline 273.15 & 197.69 & 216.03 & 28.938 & 333.59 & 360.70 & 48.810 \\
\hline 280 & 202.63 & 220.98 & 30.309 & 341.41 & 369.06 & 51.122 \\
\hline 290 & 209.96 & 228.22 & 32.371 & 352.90 & 381.24 & 54.593 \\
\hline 298.15 & 216.03 & 234.13 & 34.107 & 362.32 & 391.15 & 57.508 \\
\hline 300 & 217.42 & 235.47 & 34.508 & 364.47 & 393.40 & 58.180 \\
\hline
\end{tabular}


Table 5. Group values for estimating the heat capacity of FPB and FPU at 298.15 K using Chikcos' method [22].

\begin{tabular}{ccc}
\hline Description of group & Formula & $\begin{array}{c}\text { Values / } \\
\left(\mathrm{J} \cdot \mathrm{K}^{-1} \cdot \mathrm{mol}\right. \\
-1\end{array}$ \\
\hline tertiary aromatic $s p^{2} \mathrm{C}$ & $=\mathrm{C}_{\mathrm{a}} \mathrm{H}-$ & 17.5 \\
quaternary aromatic $s p^{2} \mathrm{C}$ & $=\mathrm{C}_{\mathrm{a}} \mathrm{R}-$ & 8.5 \\
cycliic ether & $-\mathrm{O}_{\mathrm{c}^{-}}$ & 9.71 \\
cyclic tertiary $s p^{2} \mathrm{~N}$ & $=\mathrm{N}_{\mathrm{c}^{-}}$ & 13.9 \\
Fluorine & $-\mathrm{F}$ & 24.8 \\
second $s p^{3}$ Nitrogen & $-\mathrm{NH}_{2}$ & 21.6 \\
cyclic urea & $-\mathrm{NHCONH}-$ & 63.6 \\
\hline
\end{tabular}

\section{Conclusions}

The thermodynamic properties of FPB and FPU have been investigated by means of low temperature calorimetry. The heat capacities have been measured in the temperature range from $1.9 \mathrm{~K}$ to $300 \mathrm{~K}$ using the PPMS calorimeter, and the corresponding thermodynamic functions have been calculated based on the curve fitting of the heat capacity data. The standard molar heat capacities, entropies and enthalpies at $298.15 \mathrm{~K}$ and $0.1 \mathrm{M}$ Pa have been determined to be $(216.03 \pm 2.16) \mathrm{J} \cdot \mathrm{K}^{-1} \cdot \mathrm{mol}^{-1},(234.13 \pm 2.34) \mathrm{J} \cdot \mathrm{K}^{-1} \cdot \mathrm{mol}^{-1}$ and $(34.10 \pm 0.341) \mathrm{kJ} \cdot \mathrm{mol}^{-1}$, respectively for $\mathrm{FPB}$, and $(362.32 \pm 3.62) \mathrm{J} \cdot \mathrm{K}^{-1} \cdot \mathrm{mol}^{-1},(391.15 \pm 3.91) \mathrm{J} \cdot \mathrm{K}^{-1} \cdot \mathrm{mol}^{-1}$ and $(57.50 \pm 0.575) \mathrm{kJ} \cdot \mathrm{mol}^{-1}$, respectively for FPU. As a comparison, the heat capacities of FPB and FPU at 298.15 $\mathrm{K}$ have been estimated to be $226.51 \mathrm{~J} \cdot \mathrm{K}^{-1} \cdot \mathrm{mol}^{-1}$ and 360.91 $\mathrm{J} \cdot \mathrm{K}^{-1} \cdot \mathrm{mol}^{-1}$, respectively, using the group additivity method developed by Chiockos et al. [21]. The deviations between the estimated and measured heat capacities are within $\pm 4.5 \%$ for FPB and $\pm 0.4 \%$ for FPU, suggesting that Chiockos' method is reliable for estimating heat capacities of condensed organic compounds at 298.15 K.

\section{Acknowledgements}

This work was funded by Shandong Province Natural Science Foundation of China (No. ZR2015BM015) and National Natural Science Foundation of China (No. 21473198). Quan Shi would like to thank Hundred-Talent Program founded by Chinese Academy of Sciences.

\section{References}

[1] R. Ghodsi, et al., "Design, synthesis and biological evaluation of new 2,3-diarylquinoline derivatives as selective cyclooxygenase-2 inhibitors," Bioorg. Med. Chem. 18, 1029-1033, 2010.

[2] L. M. Cornall, M. L. Mathai, D. H. Hryciw, A. J. McAinch, "GPR120 agonism as a countermeasure against metabolic deseases," Drug Discovery Today, 19, 670-679, 2014.

[3] T. Hara, et al., "Free fatty acid receptors and their role in regulation of energy metabolism," Rev. Physiol. Biochem. Pharmacol., 164, 77-116, 2013.

[4] J. R. Teerlink, "A novel approach to improve cardiac performance: cardiac myosin activators," Heart Failure Rev., 14, 289-298, 2009.

[5] S. Offermanns, "Free fatty acid (FFA) and hydroxyl carboxylic acid (HCA) receptors," Annu. Rev. Pharmacol. Toxicol., 54, 407-434, 2014.

[6] C. M. G. Azevedo, et al., "Non-acidic free fatty acid receptor 4 agonists with antidiabetic activity," J. Med. Chem., 59, 8868-8878, 2016.

[7] B. P. Morgan, et al., "Discovery of omecamtiv mecarbil the first, selective, small molecule activator of cardiac myosin," ACS Med. Chem. Lett., 1, 472-477, 2010.

[8] M. A. Schwaller, G. Dodin, J. Aubard, "Thermodynamics of drug-DNA interactions: entropy-driven intercalation and enthalpy-driven outside binding in the ellipticine series," Biopolymers, 31, 519-527, 1991.

[9] J. Sangster, "Phase diagrams and thermodynamic properties of binary systems of drugs," J. Phys. Chem. Ref. Data., 28, 889-930, 1999.

[10] J. Du, X. Wang, Z. Tan, G. Zou, "Thermodynamic investigation on para-alkyl chain-substituted phenylbicyclohexyl-type liquid crystals with difluorooxymethylene bridge," J. Therm. Anal. Calorim., doi 10.1007/s10973-016-5852-5.

[11] X. Wang, Z. Tan, Q. Shi, G. Zou, "Low-temperature heat capacities and thermodynamic functions of four-ring chain difluoromethyleneoxy liquid crystalline compounds with different alky terminal chain," J. Therm. Anal. Calorim., 125, 537-545, 2016.

[12] G. Zou, et al., "Calorimetric studies on two halogenated uracil isomers," Thermochimica Acta., 634, 6-11, 2016.

[13] Q. Shi, Z. Tan, N. Yin, "Low temperature calorimetry and its application in material research (in Chinese)," Chin. Sci. Bull., doi: 10.1360/N972016-00550.

[14] R. X. Dai, et al., "Low-temperature heat capacity and standard thermodynamic functions of $\beta$-d-(-)-arabinose (C5H10O5)," J. Chem. Thermodyn., 92, 60-65, 2016.

[15] Q. Shi, L. S. Claine, B. G. Juliana, B. F. Woodfield., "Accurate heat capacity measurements on powdered samples using a Quantum Design physical property measurement system," J. Chem. Thermodyn., 42, 11071115, 2010.

[16] Q. Shi, J. Boerio-Goates, B. F. Woodfield, “An improved technique for accurate heat capacity measurements on powdered samples using a commercial relaxation calorimeter," J. Chem. Thermodyn., 43, 1263-1269, 2011.

[17] J. M. Schliesser, B. F. Woodfield, "Lattice vacancies responsible for the linear dependence of the lowtemperature heat capacity of insulating materials," Phys. Rev. B., 024109, 2015.

[18] C. Hang, et al., "A facile peroxo-precursor synthesis method and structure evolution of large specific surface area mesoporous $\mathrm{BaSnO}_{3}$," Inorg. Chem., 54, 4002-4010, 2015.

[19] M. A. V. Ribeiro da Silva, et al., "Thermochemistry of $\alpha$ D-xylose(cr)," J. Chem. Thermodyn., 58, 20-28, 2013.

[20] X. Liu, et al., "Structural, magnetic, and thermodynamic evolutions of $\mathrm{Zn}$-doped $\mathrm{Fe}_{3} \mathrm{O}_{4}$ nanoparticles synthesized using a one-step solvothermal method," J. Phys. Chem. C., 120, 1328-1314, 2016.

[21] J. S. Chickos, D. G. Hesse, J. F. Liebman, "A group additivity approach for the estimation of heat capacities of organic liquids and solids at $298 \mathrm{~K}$," Struct. Chem., 4, 261-269, 1993.

[22] J. S. Chickos, W. E. Acree Jr, "Enthalpies of sublimation of organic and organometallic compounds. 1910-2001," J. Phys. Chem. Ref. Data., 31, 537-698, 2002. 